\title{
Low-Latitude Atmosphere-Ionosphere Effects Initiated by Strong Earthquakes Preparation Process
}

\author{
Sergey Pulinets \\ Space Research Institute, Russian Academy of Sciences, Moscow 117997, Russia \\ Correspondence should be addressed to Sergey Pulinets, pulse1549@gmail.com
}

Received 6 December 2011; Revised 9 March 2012; Accepted 18 March 2012

Academic Editor: Yuichi Otsuka

Copyright () 2012 Sergey Pulinets. This is an open access article distributed under the Creative Commons Attribution License, which permits unrestricted use, distribution, and reproduction in any medium, provided the original work is properly cited.

Ionospheric and atmospheric anomalies registered around the time of strong earthquakes in low-latitude regions are reported now regularly. Majority of these reports have the character of case studies without clear physical mechanism proposed. Here we try to present the general conception of low-latitude effects using the results of the recent author's publications, including also rethinking the earlier results interpreted basing on recently established background physical mechanisms of anomalies generation. It should be underlined that only processes initiated by earthquake preparation are considered. Segregation of low-latitude regions for special consideration is connected with the important role of ionospheric equatorial anomaly in the seismoionospheric coupling and specific character of low-latitude earthquake initiated effects. Three main specific features can be marked in low-latitude ionospheric anomalies manifestation: the presence of magnetic conjugacy in majority of cases, local longitudinal asymmetry of effects observed in ionosphere in relation to the vertical projection of epicenter onto ionosphere, and equatorial anomaly reaction even on earthquakes outside equatorial anomaly (i.e., 30-40 LAT). The equality of effects morphology regardless they observed over land or over sea implies only one possible explanation that these anomalies are initiated by gaseous emanations from the Earth crust, and radon plays the major role.

\section{Introduction}

Many studies for the ionospheric precursors of earthquakes have been done since 1964 when great Alaska "Good Friday" $\left(M_{w}=9.2\right)$ earthquake took place on the 27th of March. History of these studies is described by Pulinets and Boyarchuk [1]. We can consider the starting date of systematic studies of seismo-ionospheric coupling from publication of the book Ionospheric Precursors of the Earthquakes [2]. Pulinets [3] proposed to consider the ionospheric variations stimulated by the earthquake preparation process as one of the constituents of day-to-day ionospheric variability. This statement was questioned in some publications $[4,5]$. But after revealing the main phenomenological features of ionospheric precursors [6] and their stable and confident statistical characteristics [7-10] the discussions shifted to the direction of their physical mechanism clarification. The diversity of ionospheric effects manifestation before earthquakes (positive and negative deviations from undisturbed level, local time dependence, longitudinal effect, etc.) produced confusion in heads of physicists, and instead of unitary vision of the phenomena the diversity of the models was proposed [11]. And the most mysterious fact was the difference in precursor manifestation in high and middle latitudes and in low latitudinal regions. From the morphology of low-latitudinal effects $[12,13]$ it became clear that the only possible explanation could be found in the field of equatorial anomaly electrodynamics, and regardless the vertical anomalous electric field proposed in the previous models [14] some mechanism for generation of the zonal electric field should be provided. This question stood unresolved until the final conception of the lithosphere-atmosphereionosphere coupling appeared [15] where atmospheric effects play important role in the local modification of the global electric circuit parameters [16]. Understanding the underlying mechanism of the zonal electric field generation opened the way to complete the physical model of seismoionospheric effects in low-latitudes [17, 18].

The present paper will provide the short history of the low-latitude and equatorial effects of the earthquakes studies by the author and his group. Then the underlying physical mechanisms will be considered together with examples of 
the precursors records for the recent major earthquakes. And finally the paper will be concluded with still unresolved problems, which need further clarification.

\section{Topside Sounding Results: The First Manifestation of Low-Latitude and Equatorial Effects of Earthquakes in the Ionosphere}

Before the GPS era, in the absence of multisatellite constellations like COSMIC the only means that permitted to provide the global monitoring of the ionosphere variability at the level of the F2-layer maximum was the topside sounding [21]. And the very first results from IS-338 Intercosmos19 topside sounder $[12,13,22]$ demonstrated unexpected features of ionospheric anomalies before earthquakes in lowlatitude regions: the longitudinal asymmetry of the effect in relation to the impending earthquake epicenter position, amplification/degradation/distortion of the equatorial anomaly shape in comparison with model solution, anomaly development at a typical local time, conjugated effects (anomalous deviations are observed not only over the impending epicenter but in magnetically conjugated point of opposite hemisphere), modification of the vertical distribution of electron concentration in topside ionosphere, and effects produced by low-mid latitude earthquakes (epicenter is 10-20 degrees poleward from the equatorial anomaly crest position) on electron concentration in equatorial anomaly. Taking into account that the majority of these effects were published earlier elsewhere, only most essential points will be illustrated lower.

In the next sections following some specific features revealed mainly with the help of topside sounding will be presented. They were published elsewhere but never were collected together. The uniqueness of these data is provided by the fact that only topside sounder is able to reveal variations of the critical frequency foF2 in global scale, and over the areas without ground based ionosondes installed.

2.1. Longitudinal Features. In Figure 1 the longitudinal variation of the critical frequency foF 2 obtained with the topside sounder IS-338 at the latitude 3.2 (latitude of impending earthquake epicenter) is presented. Continuous monitoring of the longitudinal structure of the critical frequency distribution for the fixed local time demonstrated its high stability: with some variations of amplitude of critical frequency variation, its shape remained stable for the given geophysical conditions (season, solar activity, latitude, and local time). The bold line marked by number 1 is the undisturbed longitudinal distribution reflecting the so-called wave- 4 longitudinal structure discovered by Intercosmos-19 satellite $[23,24]$. The dash-dot line marked by number 2 shows the longitudinal distribution obtained 14 July 1980, 2 days before the M7.3 earthquake at New Guinea region (3.2N, 143.3E). The dashed line marked by number 3 was obtained on 15 July, 1 day before the main shock. Both distributions demonstrate the pronounced minimum in the vicinity of epicenter longitude, but the minimum on 14 July is shifted

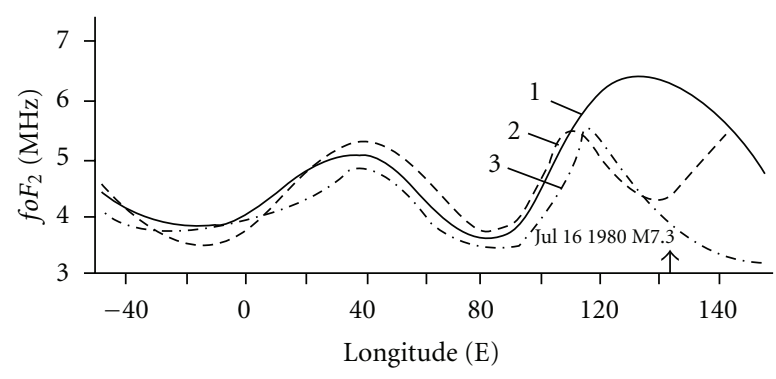

FIGURE 1: Longitudinal distributions of the critical frequency foF2 obtained by IS-338 topside sounder (Intercosmos-19 satellite) at the latitude $3 \mathrm{~N}$ for the fixed local time (05-06 LT). Bold line (1): averaged quiet time distribution; dash-dot line (2): distribution obtained for 14 July 1980; dashed line (3): distribution obtained on 15 July 1980.

to the east from the epicenter longitude. This feature was unexplained until the mechanism of preseismic anomaly formation was clarified [16].

2.2. Modification/Distortion of Equatorial Anomaly Shape. In the left panel of Figure 2 the equatorial anomaly preearthquake degradation is demonstrated 2 hours before the moderate M5.1 shock in equatorial ionosphere 06.07 1979 [13]. The right panel demonstrates how the vertical distribution of the electron concentration changed. It is differential tomographic reconstruction of the latitudinal cross-section of the equatorial anomaly, one can see now the negative depletions in the crests of equatorial anomaly and high increase of electron concentration over geomagnetic equator leading to the anomaly degradation and crests disappearance. The physical model of such changes in equatorial anomaly before earthquakes is presented in [18].

Figure 3 demonstrates other cases of equatorial anomaly distortion registered by topside sounder for different earthquakes. From left to right one can see deepening of the anomaly trough between crests, formation of crests in predawn hours, and strong distortion of equatorial anomaly with trough movement to the north from geomagnetic equator. Diversity of the observed effects implies the complex physical mechanism that should be developed to explain the observed effects in the equatorial anomaly before earthquakes.

\subsection{Effects in Equatorial Anomaly from Low-Midlatitude} Earthquakes. Interesting feature of earthquake preparation impact on equatorial anomaly was detected during the analysis of topside sounding data around the time of Mammoth Lake seismic swarm in May 1980 [25] when during 3 days the 4 shocks with magnitude $M \geq 6$ and 4 shocks with magnitude $M \geq 5.5$ took place practically at the same point $37.6^{\circ} \mathrm{N},-119^{\circ} \mathrm{W}$. In Figure 4 one can see in the left panel the consecutive maps (2D distribution of the critical frequency scaled from topside ionograms). The top map in the left panel represents the undisturbed background level. This map was constructed from several undisturbed days in May 1980. Then, under the reference maps one can see 


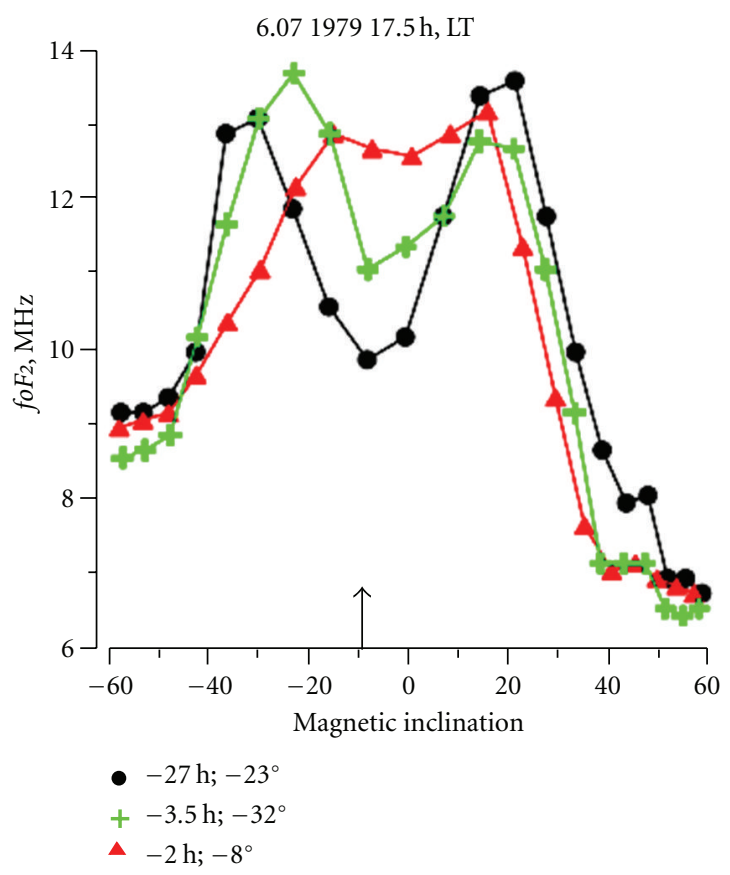

(a)

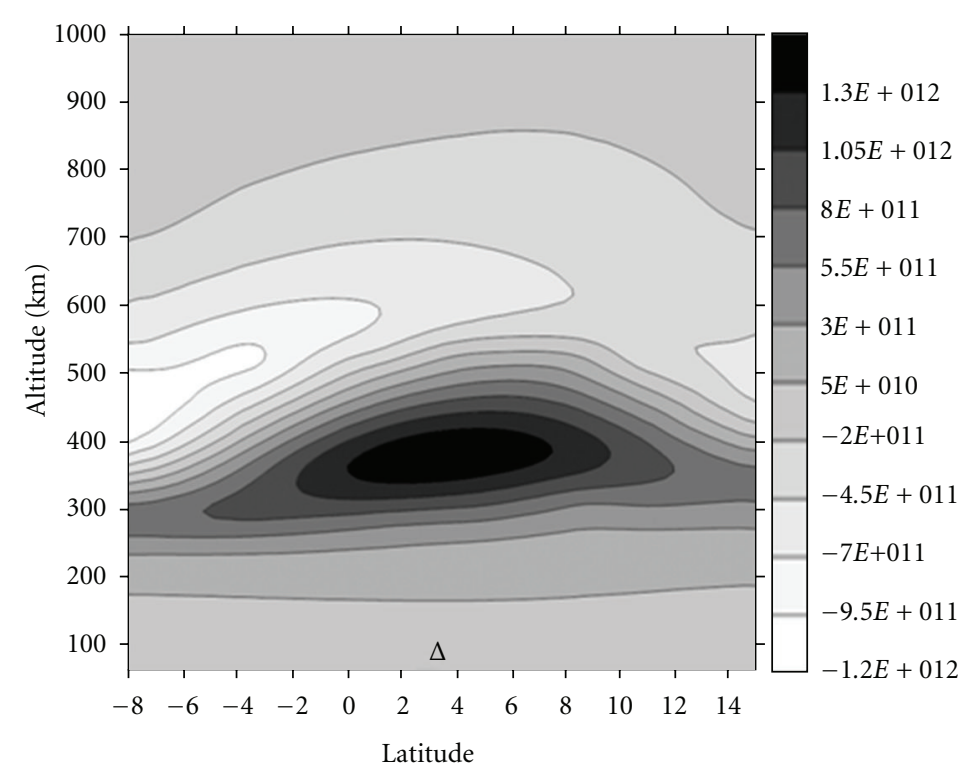

(b)

FIGURE 2: (a) consecutive passes of Intercosmos-19 satellite over equatorial anomaly. In figure legend are shown time before earthquake and longitudinal distance of the satellite orbit from the epicenter longitude sign "-" indicates satellite pass eastward and sign " + " pass westward from the epicenter longitude; (b) tomographic reconstruction of the difference of the vertical distribution of electron density between July 6 and July 51979 (red and black lines at the left panel).

the distributions obtained for the same local time 15-16 LT for the days 21, 22, 26, and 27 of May. In the right panel the differential maps (difference between the current day and the reference map) are shown. The main peculiarity observed on the differential maps is a formation of the positive anomaly close to the vertical projection of epicenter. But, in addition, one can easily observe the negative deviation in the northern crest of the equatorial anomaly. The absolute value of the critical frequency deviation is not too much (near 12\%), but in the absolute values it is more than $1 \mathrm{MHz}$. Dynamics of the latitudinal distribution of the critical frequency from 20 to 27 of May are shown in Figure 5. These distributions demonstrate one more specific feature formation of additional density maximum at latitude $20-25^{\circ} \mathrm{N}$. But still the most intriguing is the fact that the earthquake taking place far enough from the equatorial anomaly $\left(37.6^{\circ} \mathrm{N}\right)$ produces observable effect on anomaly. The possible reason for this will be discussed next.

Some authors [26] claim that there are no effects of equatorial anomaly on low-middle latitude earthquakes in Japanese region, but it seems that it is not so. As was demonstrated by Ouzounov et al. [27] the strong increase of electron concentration before the Tohoku earthquake was observed over huge territories including the equatorial anomaly.

2.4. Conjugated Effects. For the first time the magnetically conjugated effect in the ionosphere before earthquake was detected while studying ionospheric effects before the Irpinia earthquake M6.9 in Italy 23 November 1980 [28, 29]. Again, like what was demonstrated in Subsection 2.3, the effect was stimulated by the well-midlatitude earthquake (epicenter latitude $\left.40.5^{\circ} \mathrm{N}\right) .2 .5$ days before the main shock the negative anomaly was detected before sunrise (03-043 LT). This anomaly is shifted from the epicenter location by 10 degrees equatorward. Accurately placing the detected anomaly on geomagnetic map we see that its center lies on the L-shell 1.3, what corresponds to the outer edge of the northern crest of equatorial anomaly. And the similar negative anomaly is detected in magnetically conjugated area of the southern hemisphere (Figure 6). Later conjugated effects were observed regularly by in situ probes onboard the DEMETER satellite [30] and using the data of GIM and COSMIC constellation which are able to produce the global distribution of the electron concentration or GPS TEC. New data confirmed the possibility of generation of the conjugated effect by the middle latitude earthquake [17] with the use of the first principle physical model of the ionosphere. The model needs the additional zonal electric field to reproduce the earthquake effect in the ionosphere, and at the present moment the crucial question is the mechanism of such field generation.

\section{The Origin of the Anomalous Electric Field Generated by the Earthquake Preparation Process}

Recent years are marked by increased activity in creation of the models trying to explain the changes in atmospheric 


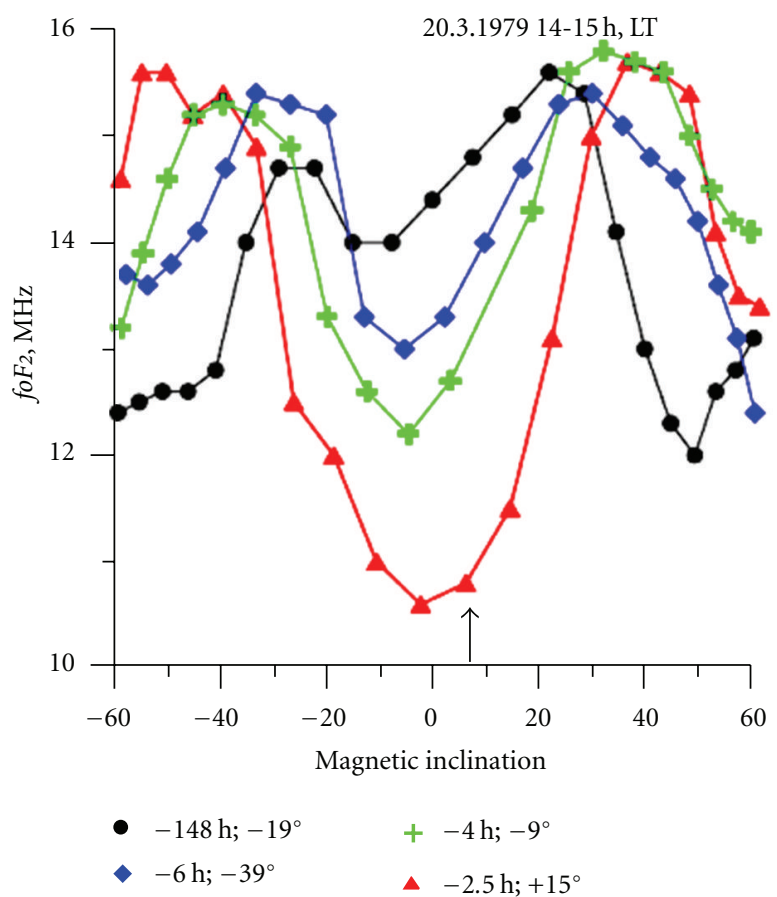

(a)

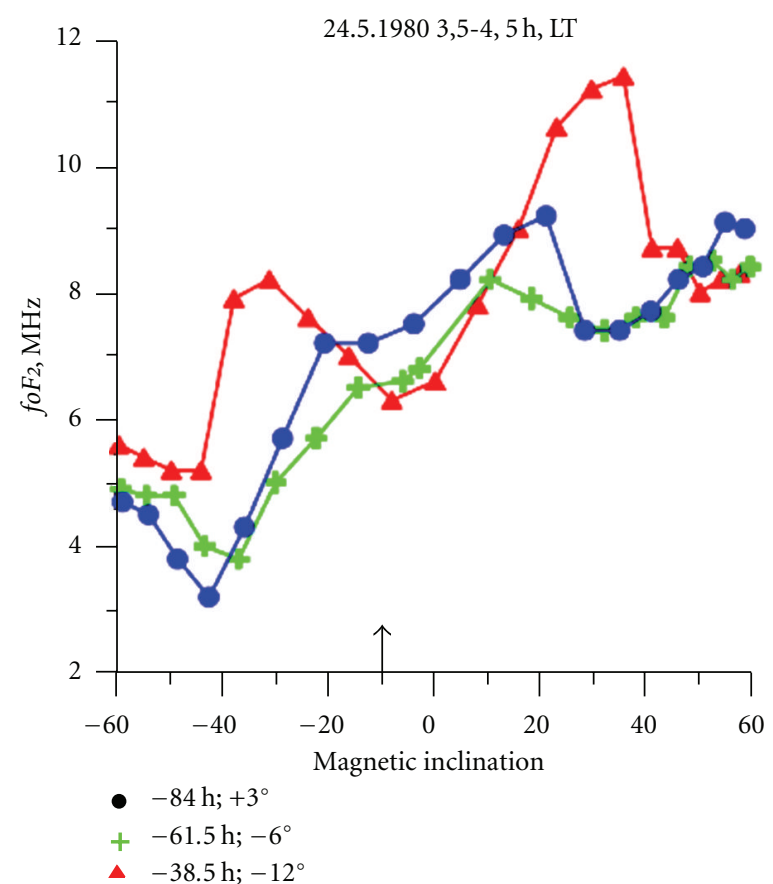

(b)

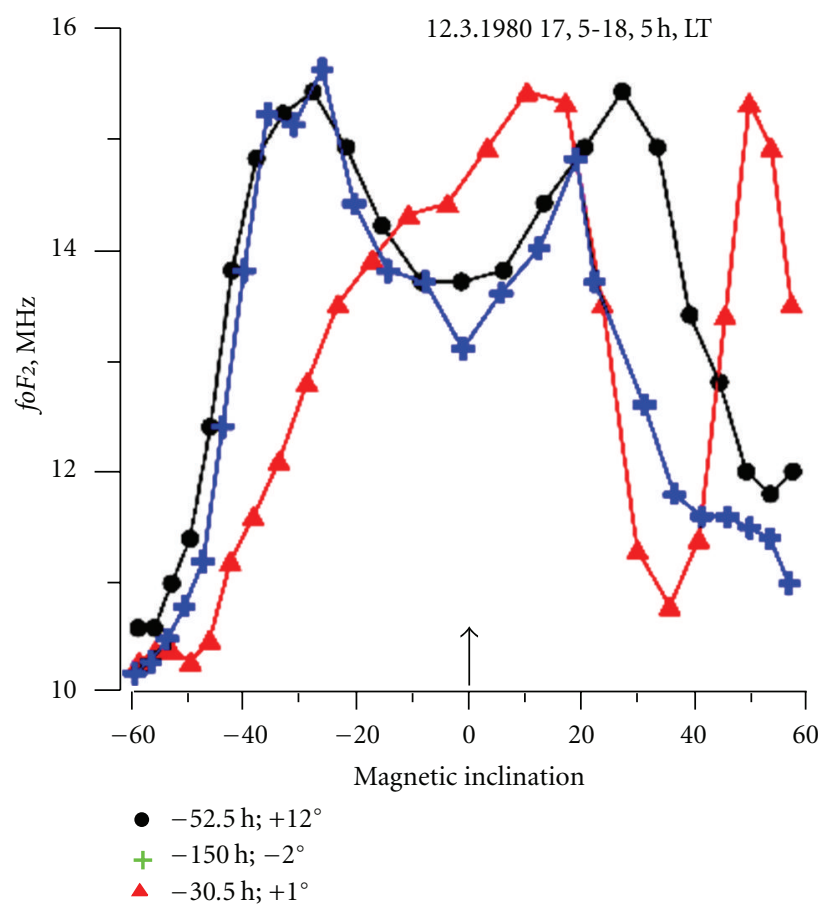

(c)

FIGURE 3: From left to right: deepening of the anomaly trough between crests, formation of crests in predawn hours, and strong distortion of equatorial anomaly with trough movement to the north from geomagnetic equator. Vertical arrows indicate the latitudinal position of the earthquake epicenter. In the figure legends the left column of numbers indicates the time (in hours) of satellite pass over the epicenter latitude in relation to the earthquake moment. Sign - indicates time before the shock and sign + time after the shock. The right column of numbers shows the longitudinal shift of the satellite orbit ground projection in relation to the epicenter longitude. 


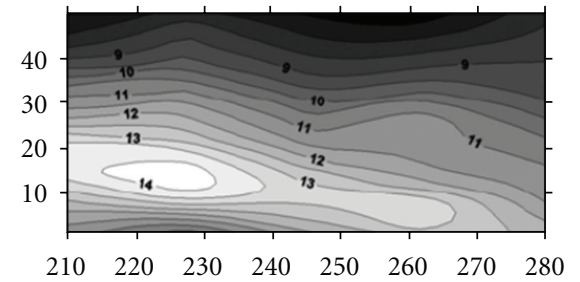

(a)

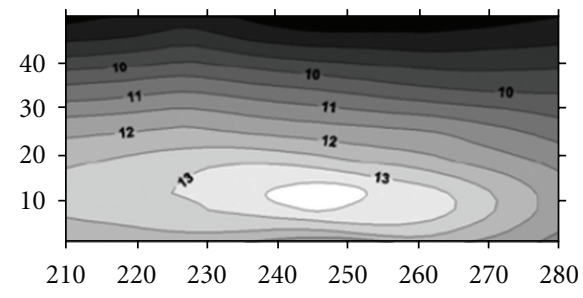

(c)

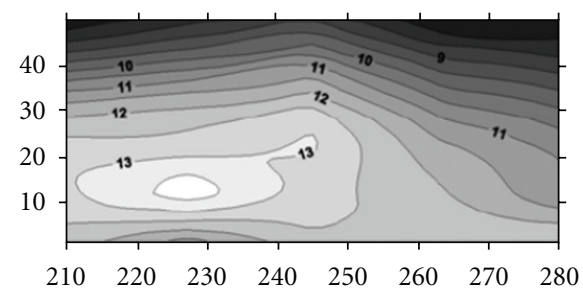

(e)

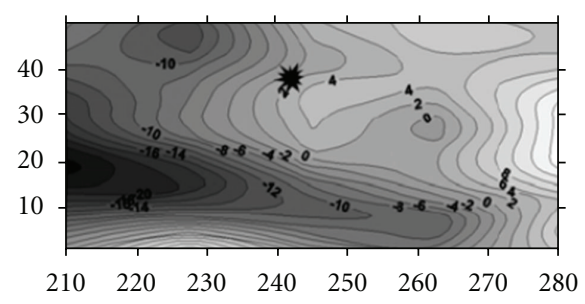

(g)

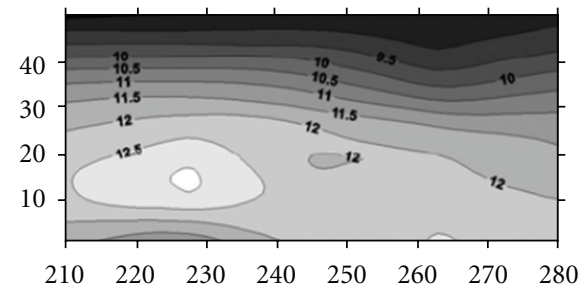

(b)

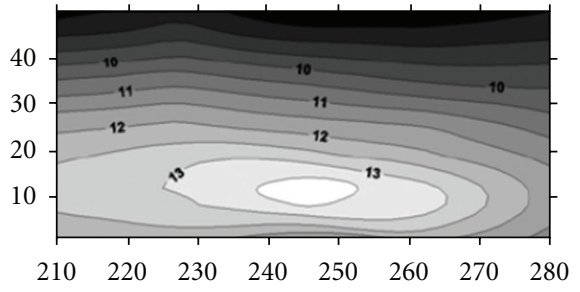

(d)

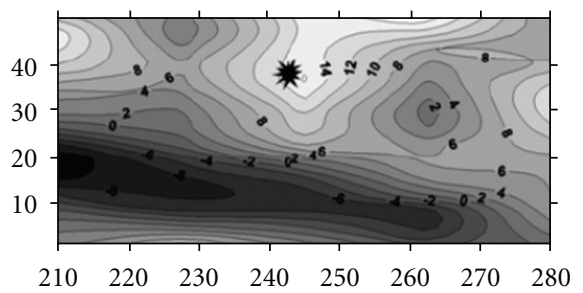

(f)

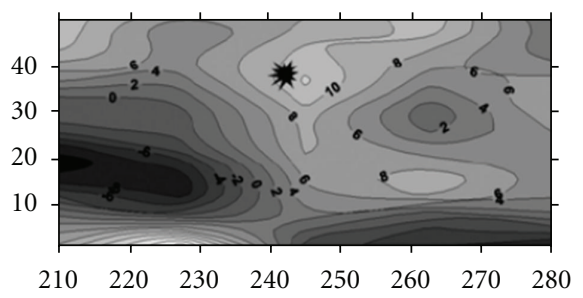

(h)

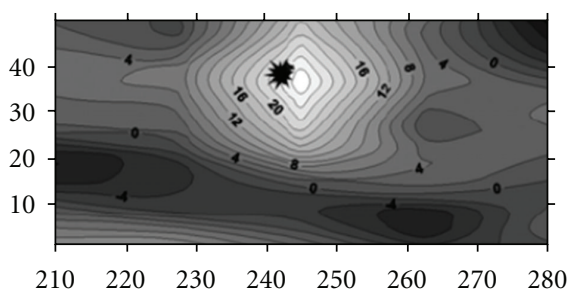

(i)

Figure 4: (a)-(e): absolute (foF2 distribution) LT maps for -15-16 LT. From (a) to (e): combined map for 15 and 19 May (undisturbed conditions, background level) and 21, 22, 26, and 27 of May. (f)-(i): the maps of the critical frequency deviation (in \% relative to the top panel in the left column). From (f) to (i): 21, 22, 26, and 27 May. The epicenter position is shown by an asterisk.

electricity before strong earthquakes [16, 19, 31, 32]. These theories became the background of the model calculations of the ionospheric effects $[17,18,33,34]$. Taking into account that results of model calculations strongly depend on the initial conditions, it is worthy to consider the reality of the proposed models of atmospheric electricity modification by earthquake preparation process.
Let us start from the model proposed by Sorokin [31]. To obtain values of the anomalous electric field in the ionosphere of order $10 \mathrm{mV} / \mathrm{m}$ (what is extremely high and comparable with magnetic storm values) Sorokin [31] proposes the so- called "external current," which is somehow generated by the charged aerosols and ions produced by the radon ionization. It is a vertical current, so it should relate somehow 


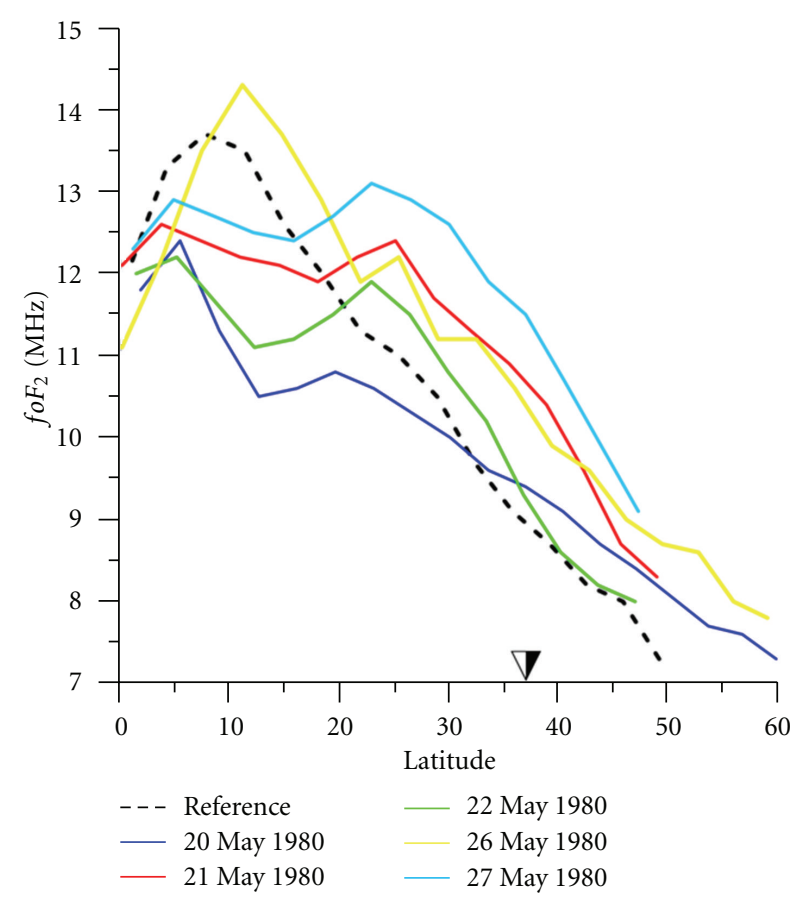

FIGURE 5: Latitudinal profiles of the critical frequency foF2 close to the epicentral longitude (Intercosmos-19 topside sounder data). Dashed black line: 19 May, color lines: 21-27 May 1980 (see legends in the figure).

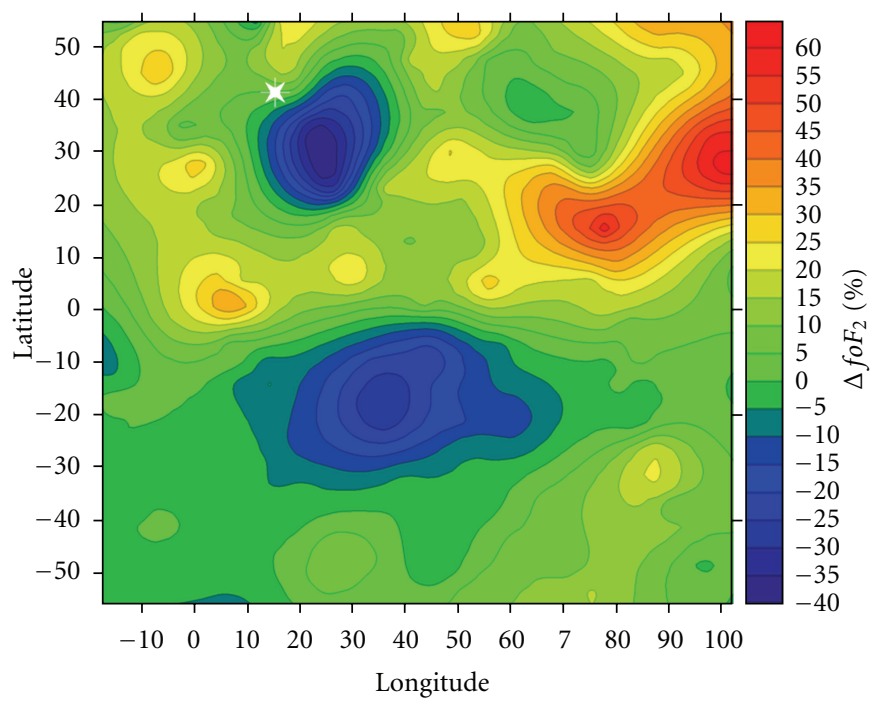

FIGURE 6: Formation of the conjugated ionospheric anomaly in the southern hemisphere before the Irpinia earthquake on 23 November 1980, M6.9, 64 hours before the main shock during predusk time (3-4 LT). White asterisk: the earthquake epicenter position.

with the natural vertical current of the global electric circuit. According to recent information [35] the vertical current density in fair weather conditions is $\sim 2 \cdot 10^{-12} \mathrm{~A} / \mathrm{m}^{2}$. Sorokin, in turn, proposes not the small adding to the natural current but the value $\sim 4 \cdot 10^{-6} \mathrm{~A} / \mathrm{m}^{2}$ at the altitude $10 \mathrm{~km}$, that is, 6 orders of magnitude higher than the natural current. In addition, looking at the figures in Sorokin's paper, this current has opposite direction in relation to the fair weather electric current direction, that is, directed up. Taking into account that the vertical current should be constant through the whole bulk of atmosphere, the same value of current should be observed not only at the altitude $10 \mathrm{~km}$ but at the ground surface as well (finally, the source of the current proposed by the author is underground). But we have no experimental evidences of such value of vertical current measured ever. It is absolutely unreal conception, and it a pity that some prominent theoreticians try to use this approach as initial conditions for the model calculations of the ionospheric effects.

Another mechanism was proposed by Freund [19] based on the solid state physics. Under the stress in the Earth crust the accumulation of positive hole charge carriers $h \bullet$ at 


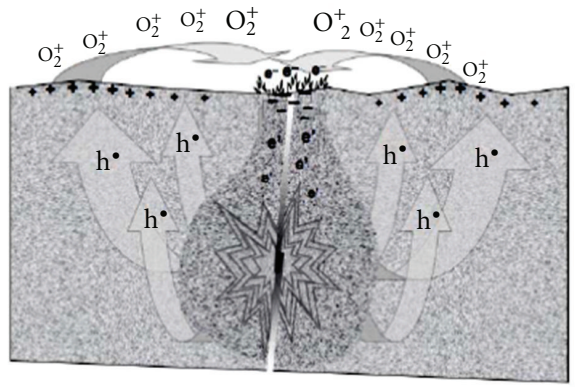

(a)

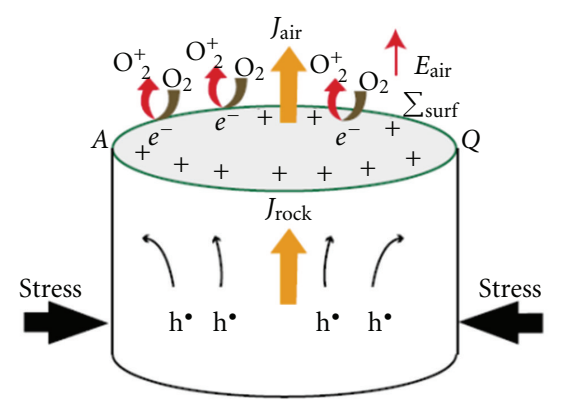

(b)

FIGURE 7: (a) conception of the positive EF field generation on the ground surface from Freund [19]; (b) modified conception of the positive EF generation on the ground surface from Koons et al. (2011).

the surface produces positive surface charges that create the vertical electric field in opposite direction to the natural one, that is, directed upwards. There exist two versions of the following development. In the first one (Figure 7(a)) somehow the ionization of air molecules happens and the flux of positive ions of $\mathrm{O}_{2}^{+}$flows into the upper layers of atmosphere. The return current is closed in corona discharge which returns positive potential into negative. What is the origin of corona discharge, and why it reverses the surface potential is not clear. In addition, we should comment that corona discharge will produce the ions of both signs, negative and positive. The second version used by Kuo et al. (Figure 7(b)) does not use the coronal discharge conception. In this version the positive ions of oxygen molecules are formed "at sharp edges of rock molecules" and go to infinity [36]. How this electric circuit is closed, not clear at all. The authors do not take into account the existence of the natural electric field at all. At the same time the natural atmospheric electric field is a fundamental feature of the global electric circuit conception, and any new electric field appearing in near ground layer of atmosphere will obviously interact with the natural one [37].

How real such conception is? No doubts that the solid physics part is absolutely correct and production of p-holes has taken place under the stress conditions. But the atmospheric part gives births to a lot of questions. Why only oxygen molecules are ionized? Atmospheric air contains a lot of gases with similar ionization potentials. So, all of them should be ionized. Positive oxygen molecules can exist in the free state in atmosphere only few nanoseconds, then they immediately enter in reactions and become hydrated. The fluxes of positive oxygen molecules in atmospheric air are completely impossible. One can find information on what happens with atmospheric air molecules after corona discharge in [20]. Figure 8 from this publication demonstrates the basic air reactions after primary ionization, from where it is clear that the fluxes of positive oxygen molecules are impossible. Actually, except the reactions shown in Figure 8 there are hundreds of other reactions forming other ions with different level of probability [38]. Every sort of these final ions will have different mobility, and to calculate the changes of atmosphere conductivity of the boundary layer is not simple task.
As concerns the surface charge, which should appear according to Freund, its propagation into the atmosphere has also serious problems. We should take into account such conception as "Coversphere" [39] The ground surface is covered by sand, clay, soil, grass, trees, and cities; we have pipelines and cables inside the near surface layer. So it is difficult to expect the pure effect like in laboratory experiments with granite or igneous rocks. And it is completely impossible to obtain such effects over the ocean surface. The statistical data of ionospheric precursory effects shown by DEMETER satellite (the most reliable source of statistical data on ionospheric precursors of earthquakes for the moment) shows that the number of ionospheric anomalies connected with earthquake is higher for the ocean, than for the land earthquakes [10]. If even to suppose that the proposed by Freund [19] mechanism works, it will be valid only for the land earthquakes, and will not work for the earthquakes which epicenter is under water surface. From the other side, there cannot be one mechanism for the land another one for the ocean earthquakes, so we should look for the other possibility.

Such possibility was proposed by Pulinets [16] (especially for the equatorial anomaly) and is connected with modification of the boundary layer conductivity by ionized action of radon emanated from the Earth crust mainly through the active tectonic faults. It should be noted in this point that according to the recent concept of radon migration in the crust, the major carrier of radon to the ground surface is the carbon dioxide and other gases such as methane, hydrogen, and helium [40]. Radon migration with gases including underwater cases is described in detail in this book. Gas discharges accompany the latest stages of earthquake preparation and bring radon to the surface even from underwater faults. Because of the novelty of this conception there no earthquake-related measurements of radon over oceans, but there are plenty of publications reporting its abundance over the ocean surface. As to the author's knowledge the first communication on the radon over the ocean surface was made by Broecker during the Symposium held in Lamont Geological Observatory (USA) in 1964 [41] This question was considered in the review paper [42] where one can find more references on 


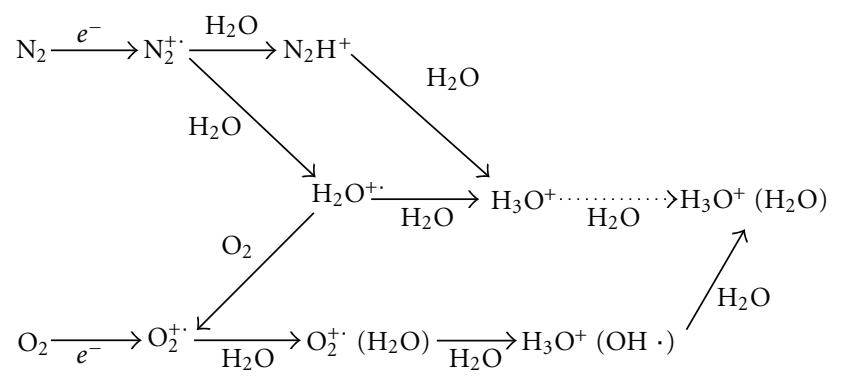

(a) Positive ion evolution

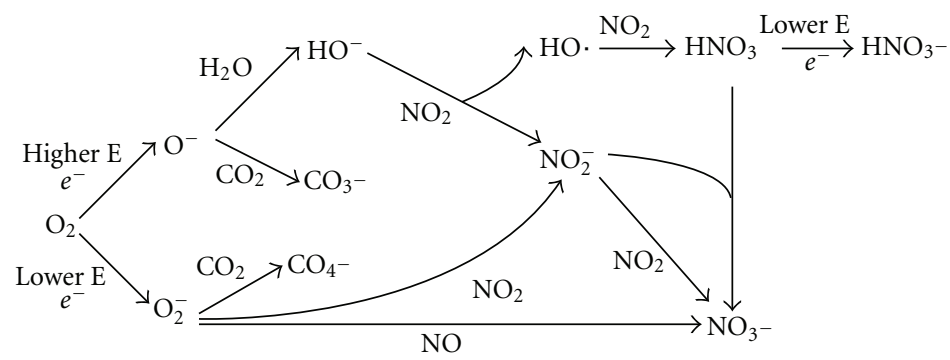

(b) Negative ion evolution

FIGURE 8: Principal ion reactions and formation the positive and negative ions after air ionization by the coronal discharge [20].

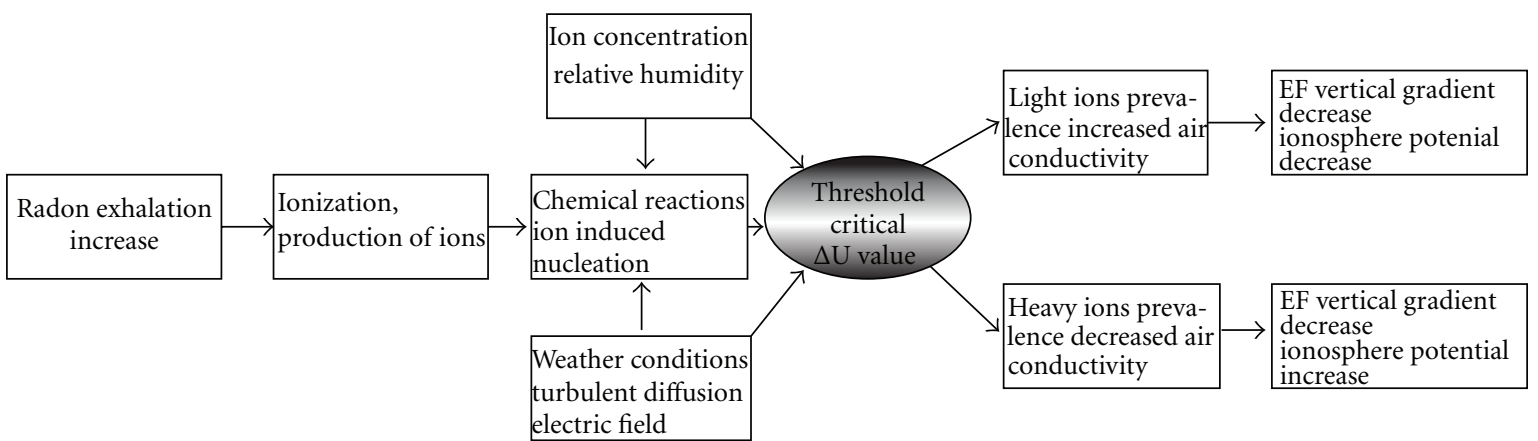

FIGURE 9: Flow chart diagram of the ionization and nucleation processes with the branching point (oval) in formation of light and heavy ions and air conductivity modification.

Broecker's publications, as more recent publications about radon measurements over the ocean surface the papers ([43] and references therein) can be proposed. Another source of radon in the near shore ocean waters (where the majority of the strong subduction earthquakes take place) is the ground water discharges carrying radon with them [44] They demonstrate the experimental evidence of the radon activity levels from underwater sources, which are sometimes much higher than for the land ones. So, the conception of air ionization with radon has no problems with both ocean and land earthquakes.

Consequences of air ionization depend on many factors such as radon activity (its concentration is different for different areas of our globe), relative air humidity (water molecules concentration determine the size to which new formed ions will grow), conditions of turbulence (the wind will remove the ions from the areas of high ion concentration changing the chemical potential correction value), air temperature (it is also determines the chemical potential correction value). The large variety of external conditions leads to the branching point in the model shown in Figure 9 [17]. In initial stages of ionization, and also under weak ionization levels the light ions will prevail in the boundary layer of atmosphere what will lead to the general increase of the bulk conductivity of atmosphere and consecutive decrease of the ionospheric potential relative to the ground. The other opportunity rises if the ionization rate is very high, relative humidity is enough to create the large ion clusters, and calm weather conditions enable forming the large clouds of aerosol size heavy ion clusters. Both cases are demonstrated in Figure 10 (geomagnetic field is directed perpendicular to the figure plane at the bottom part of 

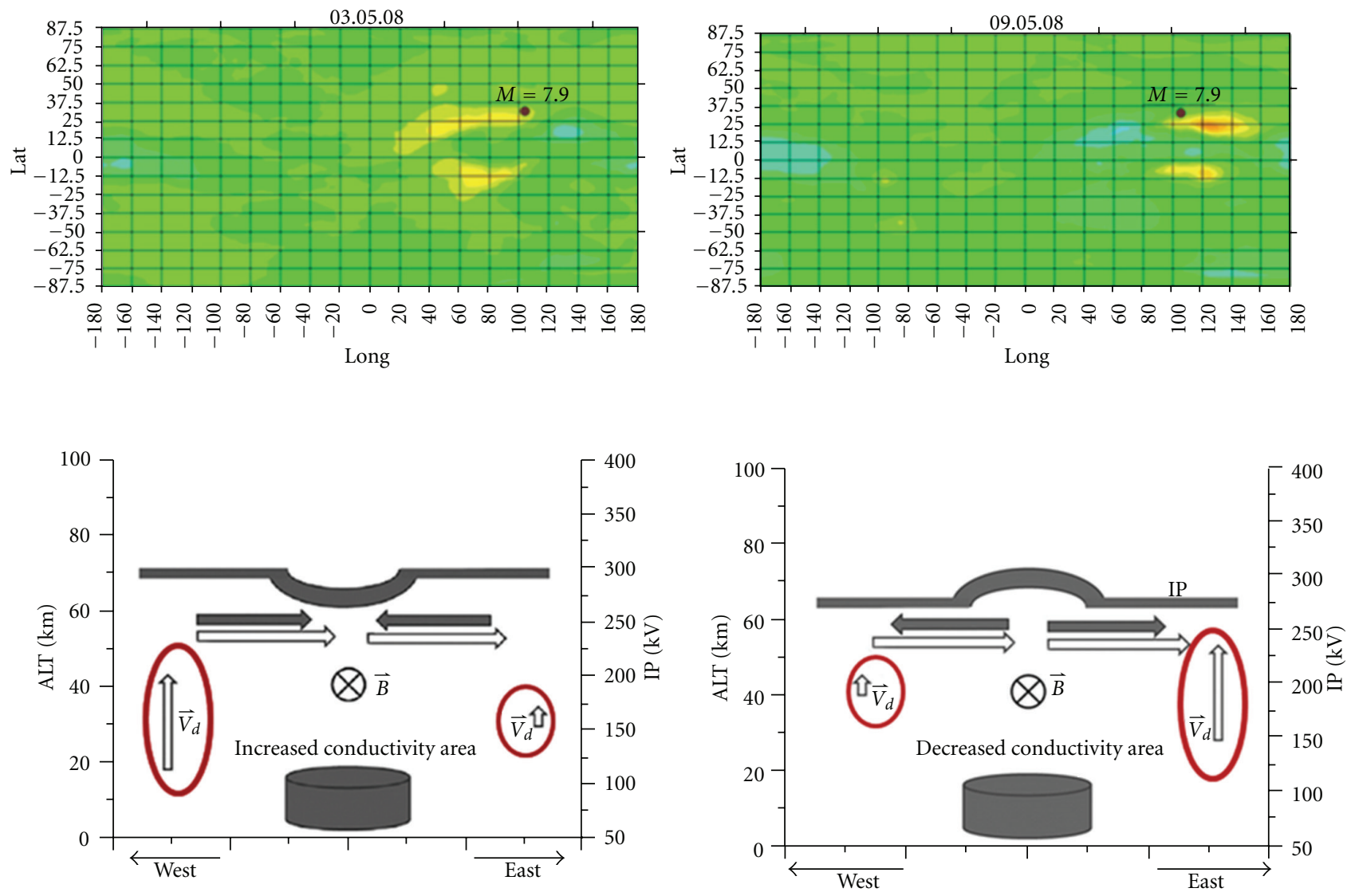

Figure 10: Bottom panel: schematic conception of atmosphere-ionosphere coupling through the global electric circuit: left panel: for condition of increased air conductivity, right panel: for condition of decreased air conductivity. Upper panel: the differential maps obtained from the GIM GPS TEC data for the period before the Wenchuan earthquake on 12 May 2008. Left panel: 2D distribution obtained on 3 of May 2008, right panel: 2D distribution obtained on 9 May 2008.

the figure). The case of increased air conductivity is shown in the left panel of the figure, and the opposite case in the right panel. In both cases the anomalous zonal electric field is formed from both sides of the ionospheric potential anomaly (dark horizontal arrows, the bottom part of the Figure 10). Because of the opposite direction of the anomalous electric field for cases of increased and decreased air conductivity, the anomalous electric field, added to the zonal electric field responsible for the equatorial anomaly formation (white horizontal arrows, the bottom part of the figure), will increase the vertical drift velocity to the west from the anomalous region in the case of increased air conductivity and to the east from the anomalous region in the case of decreased air conductivity (vertical arrows in ovals). Both cases were confirmed by the experimental results while studying the ionospheric effects of the Wenchuan earthquake [45] and are presented in the upper panel of the figure where the differential maps ( $\triangle$ TEC) using the GIM maps as a source are presented.The left panel demonstrates the configuration registered on 3 May 2009. It corresponds to the case of increased air ionization (ions only started to form and did not grow to the low mobility level). On 9 May the so-called process of ion "ageing" took place, they grew to the aerosol size (from
1 to few microns), there mobility extremely low, and air conductivity drops, what led to development of equatorial anomaly to the east from the epicenter and its degradation to the west from it.

Such experimental confirmation for the proposed physical mechanism of atmospheric electric field generation before earthquakes [16] was obtained for many cases of the recent major seismic events in low-latitude ionosphere, and seems that it could be accepted as a plausible explanation of anomalous zonal electric field generation for the further model calculations of the effects in the ionosphere.

\section{Instabilities in the Ionosphere and Plasma Bubbles Generation}

The increased vertical plasma drift (in comparison with normal undisturbed conditions) provided by anomalous seismogenic zonal electric field [16] can create the increased vertical gradient scale length favorable for generation of Rayleigh-Taylor instability [46]. The possibility of plasma bubbles formation was demonstrated in modeling experiments for intensified vertical plasma drift by Kuo et al. 


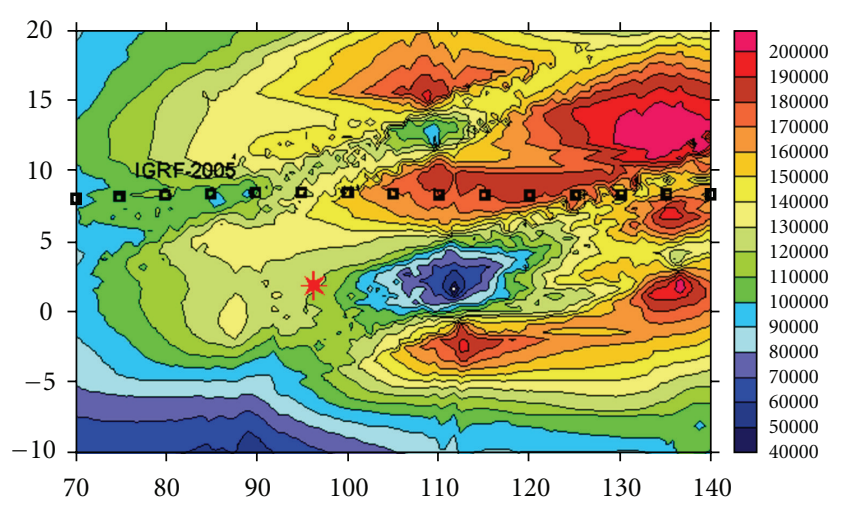

(a)

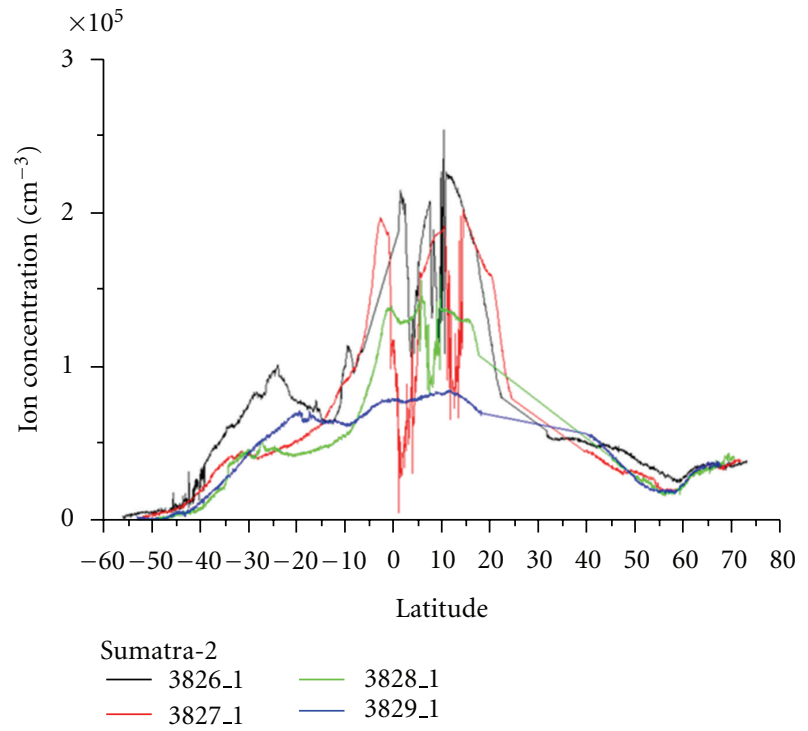

(b)

Figure 11: (a): 2D distribution of ion density obtained on board DEMETER satellite over the epicenter of the Sumatra 28 March 2005 M8.7 earthquake obtained for the night-time (22LT) on March 22 2009. (b): the latitudinal variations of the ion density for several night-time passes of DEMTER satellite over the area of preparation of the Sumatra 28 March 2005 M8.7 earthquake during one week before the seismic shock.

[34]. It is interesting to note that plasma bubbles were really registered before the Sumatra M8.7 earthquake on 28 March 2005 [30]. This effect was observed every day at night-time passes of DEMETER satellite (22 LT) during the period of one week before the main shock, and then disappeared. The 2D distribution of ion concentration for 22 March 2005 is shown in the Figure 11(a). As it was predicted by Pulinets [16] the anomaly is formed to the east from epicenter. One can see the formation of the crests of the equatorial anomaly and two depletions equatorward from the crests at both sides from the geomagnetic equator. The position of the geomagnetic equator (IGRF2005) is shown by black squares. One should keep in mind that DEMETER satellite orbit altitude at this time was $710 \mathrm{~km}$ and formation of crests at such altitude was anomalous itself, what manifested of the extremely high vertical plasma drift. Usually at these altitudes the equatorial distribution of plasma density looks like one peak over the geomagnetic equator. In Figure 11(b) the latitudinal distribution of ion density for several consecutive satellite passes over the region is shown (red one is 22 March). The shape of the distribution shows the typical plasma bubble morphology. Another check if depletions are really the plasma bubbles is the values of electron concentration and temperature which are shown at quick look plots in Figure 12. In two upper panels of Figure 12 the electron concentration and temperature are shown. The decrease of both the electron concentration and the electron temperature is characteristic only for plasma bubbles when the cold rarified plasma from the bottom ionosphere rises to the areas of the hot and dense plasma of the upper ionosphere. We can conclude that the generation of
Rayleigh-Taylor instability before the low-latitude earthquakes leading to formation of plasma bubbles is proved both experimentally and theoretically. It should be marked also that anomalous electric fields are mapped along the geomagnetic field lines into the conjugated hemisphere, what leads to the generation of anomalies from the both sides of geomagnetic equator.

One can mark in Figure 12 one more prominent feature: the strong ELF noise within the frequency band $0-250 \mathrm{~Hz}$ (the bottom panel of Figure 12). Such noises associated with plasma bubbles were registered by different space probes for many years [47]. The noises appearance coincides with the essential increase of the ion temperature. We can mark also that outside the plasma bubbles the electron temperature is $\sim 2.5$ times higher than the ions temperature. But inside the plasma bubbles the temperature tries to equalize, and even higher ion temperature than the electron one. Park et al. [48] observed two different types of plasma bubbles: normal equatorial plasma bubbles (EPBs) where temperature is usually lower than the ambient temperature, and bubbles with enhanced temperatures (BETs). They explain the appearance of BETs by fast poleward oxygen ion transport along magnetic flux tubes. To obtain such fluxes we should have some kind of the anomalous electric field to create the conditions for such drift. This situation needs the careful consideration of the electric field configuration in the upper ionosphere before earthquakes. Until the mechanism of ion heating is clear we can state only the presence of the strong gradient of the ion temperature, which can lead to generation of temperature gradient ion instability leading to the excitation of ELF turbulence. The other possibility is the different 

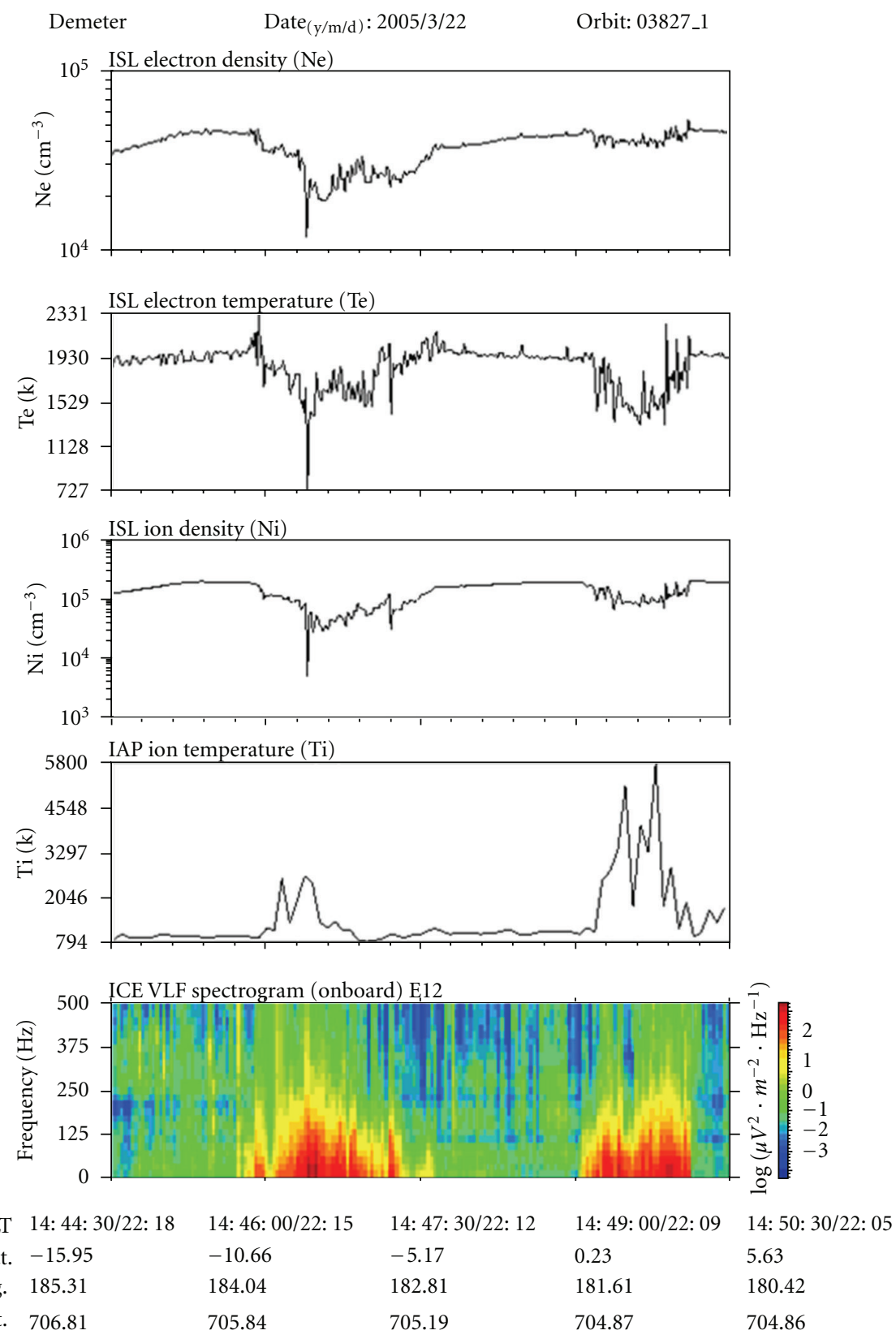

FIGURE 12: Quick look complex diagram of the DEMETER satellite data of the nigh-time pass over the area of preparation of the Sumatra 28 March 2005 M8.7 earthquake obtained on 22 March. From top to bottom: electron concentration, electron temperature, ion concentration, ion density, and dynamic spectrogram of electric component within the frequency band $0-500 \mathrm{~Hz}$.

velocities of plasma inside and outside the plasma bubble reported in [49], what can lead to stimulation of two-stream instability.

\section{Unusual Effects Connected with the Large Difference between the Geomagnetic and Geodetic Equator Positions}

The concurrence of geomagnetic conjunction and plasma transequatorial transport due to temperature gradient (summer-winter hemisphere) can produce unusual results like what happened before the Haiti earthquake [50]. As one can see from Figure 13, the equatorial anomaly geographically almost completely lies in the southern hemisphere: the vertical line marks the position of the geodetic equator. Such configuration is probably the reason of the formation of the additional density enhancement at low-middle latitudes. According to Rishbeth [51] the seasonal asymmetry of the equatorial anomaly is formed due to the meridional wind from the summer hemisphere to the winter one. The neutral wind involves in its motion the charged component, and this 


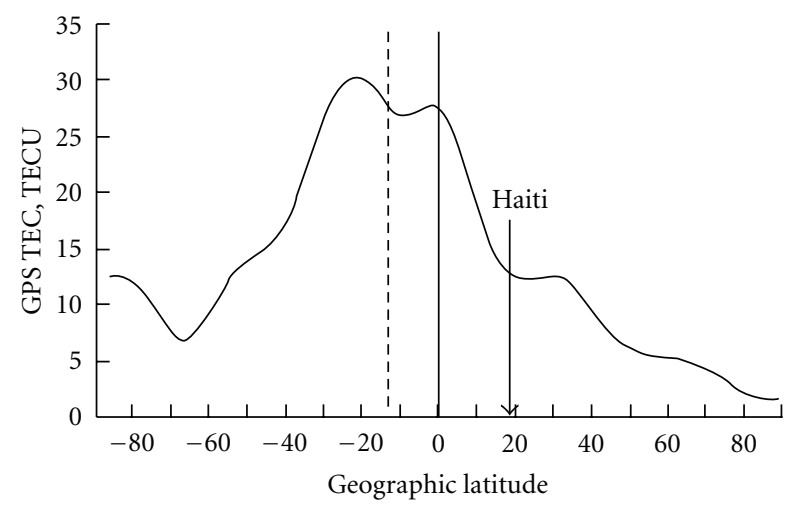

FIGURE 13: Configuration of the equatorial anomaly in relation to the geodetic equator position at the longitude of Haiti M7.9 earthquake on January 12, 2010.

leads to an increase in the concentration of the winter crest of the equatorial anomaly. But at these longitudes the winter crest of the equatorial anomaly geographically is also in the southern hemisphere. That why the wind carrying with it the denser plasma slips over the northern crest and deposits it at more high latitude region form the additional maximum at latitude near $30^{\circ} \mathrm{N}$. The Haiti earthquake epicenter was situated exactly between the northern crest of the equatorial anomaly and this additional peak of ionization. The anomalous seismogenic electric field led to the complex modification of this configuration, which was expressed in the following effects:

(i) total depletion of the electron content inside the equatorial anomaly during 6 days preceding the earthquake,

(ii) local increase in the electron concentration in the ionospheric region at the epicenter latitude between the northern crest of the equatorial anomaly and additional peak of ionization at the latitude $30^{\circ} \mathrm{N}$,

(iii) amplification of the additional maximum of ionization at latitude of $30^{\circ} \mathrm{N}$ and formation of an additional maximum at the magnetically conjugated point.

The last item needs a special comment. It demonstrates the geomagnetic feedback from the modification in the northern hemisphere to the southern one what was demonstrated in Section 2.4.

\section{Conclusions}

The processes taking place in the low-latitude ionosphere before strong earthquakes were described using the data of the satellite and ground based measurements, as well as the data of modeling. The earlier results obtained in 1979-1980 from topside sounding (Intercosmos-19 satellite) were confirmed by the data of the latest space probes such as DEMETER satellite and GPS TEC data. The origin of the ionospheric anomalies is in the ionization of the boundary layer of atmosphere and consequent changes of its electric conductivity which then leads to the changes of the ionosphere potential through the global electric circuit. It is the universal mechanism of the atmosphere-ionosphere coupling.

The deviations of electron concentration may be both positive and negative, and configuration of these variations depends on many factors. The most characteristic features are: the longitudinal asymmetry, the conjugated effect (anomalous deviations are observed not only in the vicinity of the impending earthquake epicenter vertical projection, but also in the magnetically conjugated hemisphere), the low-middle latitude earthquakes also produce the effects in equatorial anomaly, as well as in the magnetically conjugated region.

The contemporaneous ionospheric models are able adequately reproduce effects in the low-latitude ionosphere, but the initial conditions, especially the mechanism of the anomalous electric field at the ground level (or modification of atmospheric electricity in the form of air conductivity), should be established more precisely.

\section{Acknowledgments}

The research leading to these results has received funding from the European Union Sevenths Framework Program (FP7/20017-2013) under Grant Agreement no. 263502-PREEARTHQUAKES project: Processing Russian and European EARTH Observations for Earthquake Precursors Studies. The paper reflects only the author's views and the European Union is not liable for any use that may be made of the information contained herein.

\section{References}

[1] S. A. Pulinets and K. A. Boyarchuk, Ionospheric Precursors of Earthquakes, Springer, New York, NY, USA, 2004.

[2] V. A. Liperovsky, O. A. Pokhotelov, and S. A. Shalimov, Ionospheric Precursors of the Earthquakes, Nauka, Moscow, Russia, 1992.

[3] S. A. Pulinets, "Seismic activity as a source of the ionospheric variability," Advances in Space Research, vol. 22, no. 6, pp. 903906, 1998.

[4] S. S. Kouris, P. Spalla, and B. Zolesi, "Could ionospheric variations be precursors of a seismic event? A short discussion," Annali di Geofisica, vol. 44, no. 2, pp. 395-402, 2001.

[5] H. Rishbeth, "Do earthquake precursors really exist?" Eos, vol. 88, no. 29, p. 296, 2007.

[6] S. A. Pulinets, A. D. Legen'ka, T. V. Gaivoronskaya, and V. K. Depuev, "Main phenomenological features of ionospheric precursors of strong earthquakes," Journal of Atmospheric and Solar-Terrestrial Physics, vol. 65, no. 16-18, pp. 1337-1347, 2003.

[7] J. Y. Liu, Y. J. Chuo, S. J. Shan et al., "Pre-earthquake ionospheric anomalies registered by continuous GPS TEC measurements," Annales Geophysicae, vol. 22, no. 5, pp. 15851593, 2004.

[8] J. Y. Liu, Y. I. Chen, Y. J. Chuo, and C. S. Chen, "A statistical investigation of preearthquake ionospheric anomaly," Journal of Geophysical Research A, vol. 111, no. 5, Article ID A05304, 2006. 
[9] J. Y. Liu, C. H. Chen, Y. I. Chen, W. H. Yang, K. I. Oyama, and K. W. Kuo, "A statistical study of ionospheric earthquake precursors monitored by using equatorial ionization anomaly of GPS TEC in Taiwan during 2001-2007," Journal of Asian Earth Sciences, vol. 39, no. 1-2, pp. 76-80, 2010.

[10] M. Parrot, "Statistical analysis of Ionospheric Perturbations Observed by DEMETER in Relation with the Seismic Activity," Earthquake Science, vol. 24, no. 6, pp. 513-521, 2011.

[11] V. A. Liperovsky, O. A. Pokhotelov, C. V. Meister, and E. V. Liperovskaya, "Physical models of coupling in the lithosphereatmosphere-ionosphere system before earthquakes," Geomagnetism and Aeronomy, vol. 48, no. 6, pp. 795-806, 2008.

[12] S. A. Pulinets, A. D. Legen'ka, and V. Kh. Depuev, "Pre-seismic effects on the equatorial anomaly," in 10th International symposium on Equatorial Aeronomy (ISEA '00), Antalya, Turkey, May 2000.

[13] S. A. Pulinets and A. D. Legen'ka, "Dynamics of the nearequatorial ionosphere prior to strong earthquakes," Geomagnetism and Aeronomy, vol. 42, no. 2, pp. 227-232, 2002.

[14] S. A. Pulinets, K. A. Boyarchuk, V. V. Hegai, V. P. Kim, and A. M. Lomonosov, "Quasielectrostatic model of atmosphere-thermosphere-ionosphere coupling," Advances in Space Research, vol. 26, no. 8, pp. 1209-1218, 2000.

[15] S. Pulinets and D. Ouzounov, "Lithosphere-AtmosphereIonosphere Coupling (LAIC) model-an unified concept for earthquake precursors validation," Journal of Asian Earth Sciences, vol. 41, no. 4-5, pp. 371-382, 2011.

[16] S. A. Pulinets, "Physical mechanism of the vertical electric field generation over active tectonic faults," Advances in Space Research, vol. 44, no. 6, pp. 767-773, 2009.

[17] M. V. Klimenko, V. V. Klimenko, I. E. Zakharenkova, S. A. Pulinets, B. Zhao, and M. N. Tsidilina, "Formation mechanism of great positive TEC disturbances prior to Wenchuan earthquake on May 12, 2008," Advances in Space Research, vol. 48, no. 3, pp. 488-499, 2011.

[18] M. V. Klimenko, V. V. Klimenko, I. E. Zakharenkova, and S. A. Pulinets, "Variations of equatorial electrojet as possible seismo-ionospheric precursor at the occurrence of TEC anomalies before strong earthquake," Advances in Space Research, vol. 49, pp. 509-517, 2012.

[19] F. Freund, "Toward a unified solid state theory for preearthquake signals," Acta Geophysica, vol. 58, no. 5, pp. 719766, 2010.

[20] K. Sekimoto and M. Takayama, "Fundamental processes of corona discharge, surface analysis of traces stained with discharge on brass plate in negative corona," Journal of the Institute of Electrostatics Japan, vol. 33, no. 1, pp. 38-42, 2009.

[21] S. A. Pulinets and R. F. Benson, Radio-Frequency Sounders in Space, Review of Radio Science, W. Ross Stone, Ed., Oxford University Press, 1999.

[22] S. A. Pulinets, A. D. Legen'ka, A. T. Karpachev et al., "The earthquakes prediction possibility on the base of topside sounding data," IZMIRAN preprint N 34a(981), 25 p., 1991.

[23] N. P. Benkova, M. G. Deminov, A. T. Karpachev et al., "Longitude features shown by topside sounder data and their importance in ionospheric mapping," Advances in Space Research, vol. 10, no. 8, pp. 57-66, 1990.

[24] G. F. Deminova, "Wavelike structure of longitudinal variations of the nighttime equatorial anomaly," Geomagnetism and Aeronomy, vol. 35, no. 4, pp. 576-579, 1996.

[25] S. A. Pulinets and V. H. Depuev, "Ionospheric variability around the time of Mammoth Lakes seismic swarm of May 1980 in California," Proceedings of the IRI Task Force Activity 2003, ICTP Publishing, IC/IR/2004/1, pp. 85-96, 2004.
[26] S. Kon, M. Nishihashi, and K. Hattori, "Ionospheric anomalies possibly associated with $\mathrm{M} \geq 6.0$ earthquakes in the Japan area during 1998-2010: case studies and statistical study," Journal of Asian Earth Sciences, vol. 41, no. 4-5, pp. 410-420, 2011.

[27] D. Ouzounov, S. Pulinets, A. Romanov et al., "AtmosphereIonosphere Response to the M9 Tohoku Earthquake Revealed by Joined Satellite and Ground Observations: Preliminary Results," Earthquake Science, vol. 24, pp. 557-564, 2011.

[28] S. A. Pulinets and A. D. Legen'ka, "First simultaneous observations of the topside density variations and VLF emissions before the Irpinia earthquake, November, 23, 1980 in magnetically conjugated regions," in Proceedings of the International Workshop on Seismo Electromagnetics, pp. 56-59, Chofu, Japan, 1997.

[29] S. A. Pulinets, P. Biagi, V. Tramutoli, A. D. Legen'ka, and V. K. Depuev, "Irpinia earthquake 23 November 1980-lesson from nature reviled by joint data analysis," Annals of Geophysics, vol. 50, no. 1, pp. 61-78, 2007.

[30] S. Pulinets, D. Ouzounov, and M. Parrot, "Conjugated nearequatorial effects registered by DEMETER satellite before Sumatra earthquake M8.7 of March 28, 2005," in DEMETER Workshop, Toulouse, France, June 2006.

[31] V. M. Sorokin, "Plasma and electromagnetic effects in the ionosphere related to the dynamics of charged aerosols in the lower atmosphere," Russian Journal of Physical Chemistry B, vol. 1, no. 2, pp. 138-170, 2007.

[32] F. T. Freund, I. G. Kulahci, G. Cyr et al., "Air ionization at rock surfaces and pre-earthquake signals," Journal of Atmospheric and Solar-Terrestrial Physics, vol. 71, no. 17-18, pp. 1824-1834, 2009.

[33] A. A. Namgaladze, M. V. Klimenko, V. V. Klimenko, and I. E. Zakharenkova, "Physical mechanism and mathematical modeling of earthquake ionospheric precursors registered in total electron content," Geomagnetism and Aeronomy, vol. 49, no. 2, pp. 252-262, 2009.

[34] C. L. Kuo, J. D. Huba, G. Joyce, and L. C. Lee, "Ionosphere plasma bubbles and density variations induced by preearthquake rock currents and associated surface charges," Journal of Geophysical Research, vol. 116, Article ID A10317, 2011.

[35] M. J. Rycroft and R. G. Harrison, "Electromagnetic atmosphere-plasma coupling: the global atmospheric electric circuit," Space Science Reviews. In press.

[36] C. L. Kuo, J. D. Huba, G. Joyce, and L. C. Lee, "Ionosphere plasma bubbles and density variations induced by preearthquake rock currents and associated surface charges," Journal of Geophysical Research A, vol. 116, no. 10, Article ID A10317, 2011.

[37] W. A. Hoppel, "Theory of the electrode effect," Journal of Atmospheric and Terrestrial Physics, vol. 29, no. 6, pp. 709-721, 1967.

[38] K. A. Boyarchuk, A. V. Karelin, and R. V. Shirokov, Basic Models of the Ionized Atmosphere Kinetics, FGUP "NPP VNIIEM", Moscow, Russia, 2006.

[39] K. Qin, L. Wu, and G. Quo, "Multi-parameters thermal anomalies before New Zealand Ms7.0 earthquake," in Geoscience and Remote Sensing Symposium (IGARSS '11), pp. 2496-2499, 2011.

[40] L. F. Khilyuk, G. V. Chillingar, J. O. Robertson Jr., and B. Endres, Gas Migration. Events Preceding Earthquakes, Gulf Publiching Company, Houston, Tex, USA, 2000.

[41] W. S. Broecker, "An application of natural radon to problems in ocean circulation," in Symposium on Diffusion in Oceans and Fresh Waters, pp. 116-145, Palisades, NY, USA, 1964. 
[42] G. Schumann, "Radon isotopes and daughters in the atmosphere," Archiv für Meteorologie, Geophysik und Bioklimatologie Serie A, vol. 21, no. 2-3, pp. 149-170, 1972.

[43] H. Kawabata, H. Narita, K. Harada, S. Tsunogai, and M. Kusakabe, "Air-sea gas transfer velocity in stormy winter estimated from radon deficiency," Journal of Oceanography, vol. 59, no. 5, pp. 651-661, 2003.

[44] N. Jacob, D. S. Suresh Babu, and K. Shivanna, "Radon as an indicator of submarine groundwater discharge in coastal regions," Current Science, vol. 97, no. 9, pp. 1313-1320, 2009.

[45] S. A. Pulinets, V. G. Bondur, M. N. Tsidilina, and M. V. Gaponova, "Verification of the concept of seismoionospheric coupling under quiet heliogeomagnetic conditions, using the Wenchuan (China) earthquake of May 12, 2008, as an example," Geomagnetism and Aeronomy, vol. 50, no. 2, pp. 231-242, 2010.

[46] R. W. Schunk and A. F. Nagy, Ionospheres: Physics, Plasma Physics and Chemistry, Cambridge University Press, Cambridge, UK, 2000.

[47] H. C. Koons, J. L. Roeder, and P. Rodriguez, "Plasma waves observed inside plasma bubbles in the equatorial $\mathrm{F}$ region," AEROSPACE REPORT NO. TR-98(8570)-1, The Aerospace Corporation Publishing, El Segundo, Calif, USA, pp. 45774583, 1988.

[48] J. Park, K. W. Min, V. P. Kim et al., "Equatorial plasma bubbles with enhanced ion and electron temperatures," Journal of Geophysical Research A, vol. 113, no. 9, Article ID A09318, 2008.

[49] C. S. Huang, O. De La Beaujardiere, R. F. Pfaff et al., "Zonal drift of plasma particles inside equatorial plasma bubbles and its relation to the zonal drift of the bubble structure," Journal of Geophysical Research A, vol. 115, no. 7, Article ID A07316, 2010.

[50] S. A. Pulinets and K. G. Tsybulya, "Unique variations of the total electron content in the preparation period of Haitian earthquake (M7.9) on January 12, 2010," Geomagnetism and Aeronomy, vol. 50, no. 5, pp. 686-689, 2010.

[51] H. Rishbeth, "Dynamics of the equatorial F-region," Journal of Atmospheric and Terrestrial Physics, vol. 39, no. 9-10, pp. 1159$1168,1977$. 

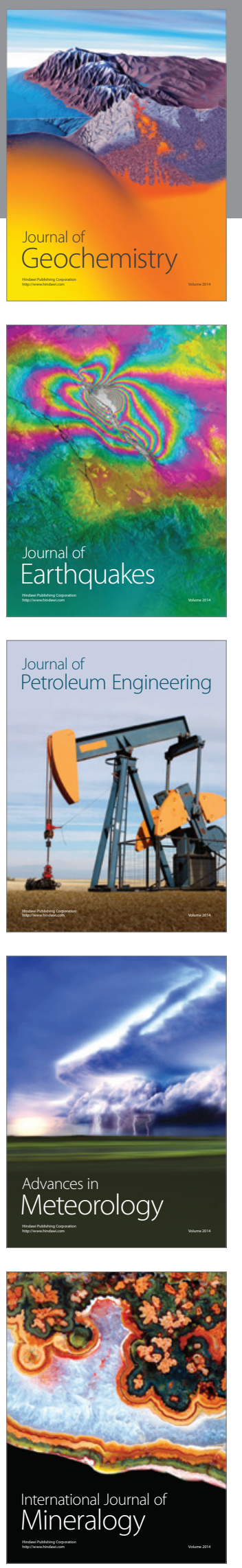
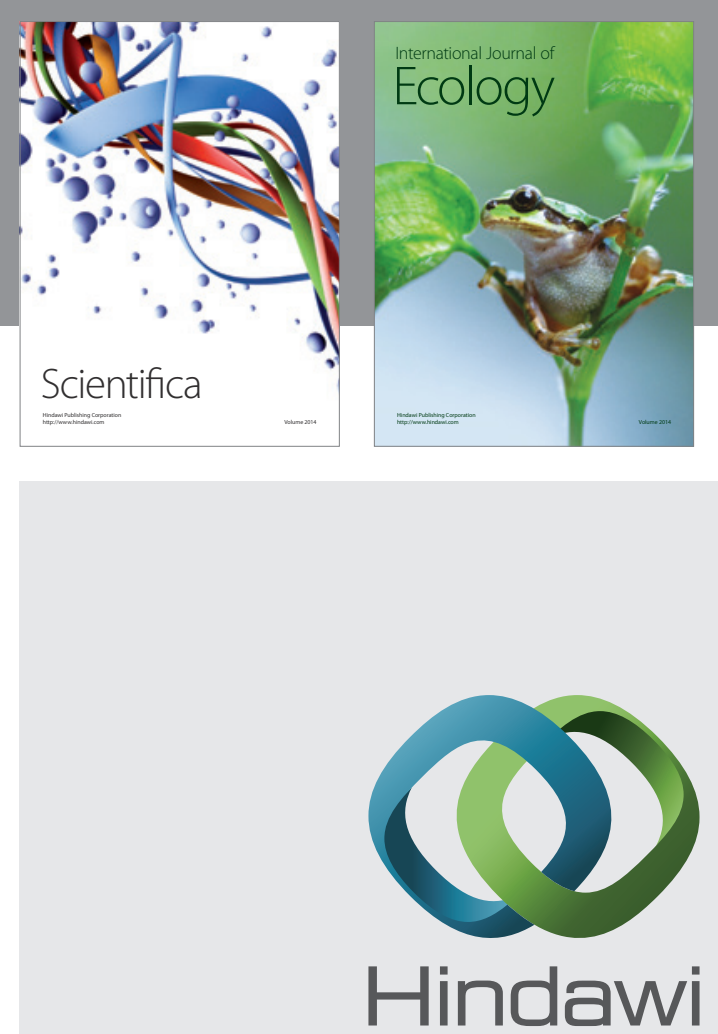

Submit your manuscripts at http://www.hindawi.com
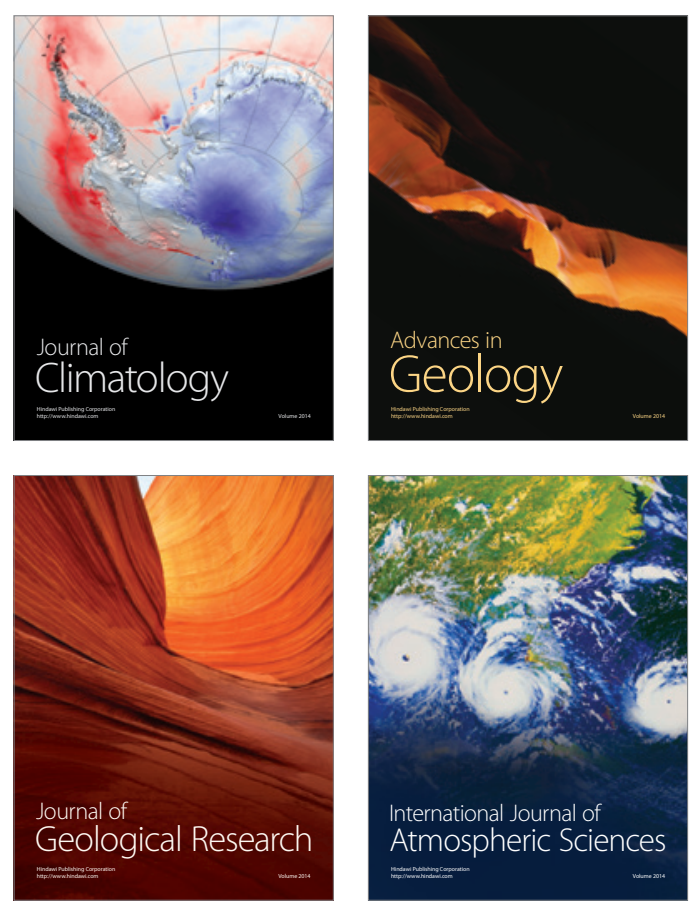
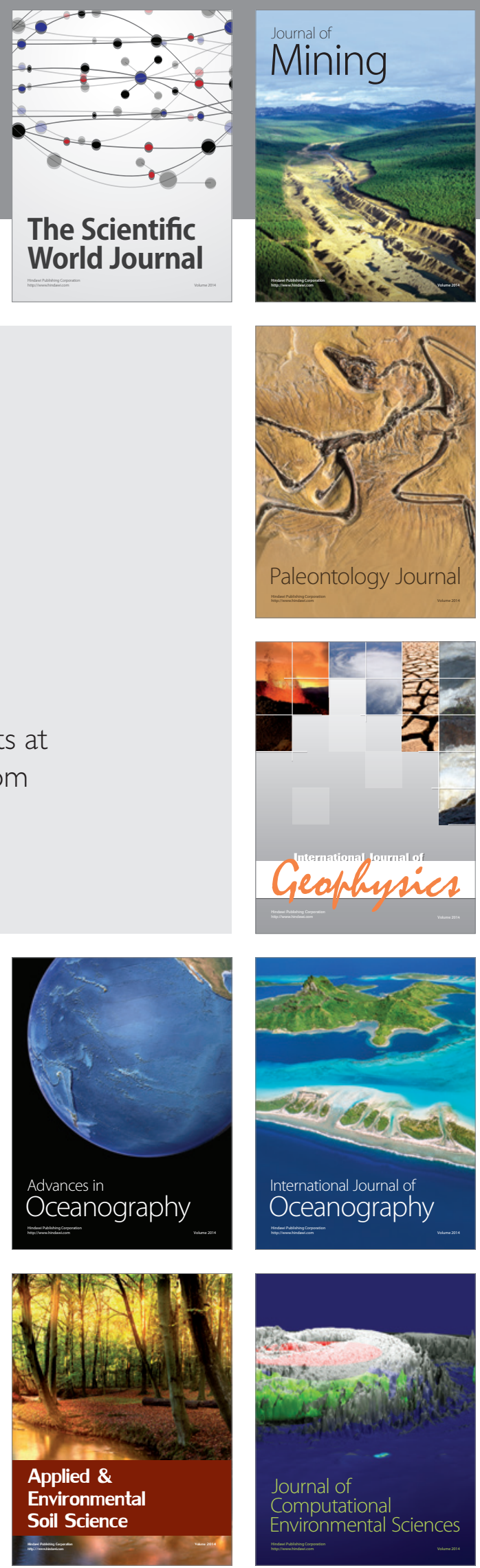